\title{
Non-invasive estimation by cross sectional echocardiography of myocardial damage in cardiomyopathy
}

\author{
MOTONAO TANAKA, SHINICHI NITTA, KEIKO NITTA, YUTAKA SOGO, \\ ATSUKO YAMAMOTO, YOSHIAKI KATAHIRA, NORIKO SATO, HIROAKI OHKAWAI, \\ FUMIAKI TEZUKA` \\ From the Department of Medical Engineering and Cardiology, Research Institute for Chest Diseases and Cancer, \\ Tohoku University; and the *Department of Pathology, Faculty of Medicine, Tohoku University, Sendai, Fapan
}

SUMMARY Retrospective and prospective studies of high resolution cross sectional echocardiograms were undertaken in order to establish an ultrasonic method for the non-invasive estimation of degeneration and fibrosis of the endomyocardium in cases of cardiomyopathy. When the echocardiograms of the ventricular wall were compared with the histological specimens intense abnormal echoes were seen at the sites of myocardial degeneration and fibrosis of the ventricular wall. The abnormal echoes classified into five types: types I, II, III-1, III-2, and III-3. Type I and type III-1 echoes were the strongest followed by those of types II and III-2, and then those of type III-3. The intensity of the abnormal echoes was 5-20 decibels stronger than that from intact tissue and was closely related to the consistency and density of the diseased tissue.

These findings strongly suggest that the boundary between degeneration or fibrosis and the intact normal myocardium was the source of the abnormal myocardial echoes and that the extent and the pattern of the distribution of the sites of degeneration and fibrosis in the myocardium were reflected in the echo patterns. Thus the tissue characteristics of the sites of degeneration or fibrosis of the myocardium may be determined non-invasively by measuring the echo intensity.

The degree of pathological change in myocardial tissue in cardiomyopathy varies from a slight increase in fibrous tissue in the myocardium to massive degeneration or a pronounced increase in interstitial fibrous tissue throughout the myocardium. Nevertheless, cardiac function is largely related to the extent of the myocardial damage. The detection of myocardial degeneration or fibrosis and the evaluation of their extent are, therefore, indispensable for the clinical evaluation of patients.

We have used ultrasonic methods for noninvasively evaluating the changes in tissue characteristics of the valves ${ }^{1-3}$ and the myocardium in patients with valvar disease ${ }^{4} 5$ and myocardial infarction. ${ }^{6}$

Requests for reprints to Professor Motonao Tanaka, Department of Medical Engineering and Cardiology, The Research Institute for Chest Diseases and Cancer, Tohoku University, 4-1 Seiryomachi, Sendai 980, Japan.

Accepted for publication 14 August 1984
The present study was undertaken to assess the applicability of cross sectional echocardiography for detecting myocardial damage in patients with cardiomyopathy. The echocardiographic findings were analysed and compared with those of histological specimens. In addition, studies were undertaken to determine the characteristics of the abnormal echoes of the myocardium by sensitivity graded paired echocardiography. ${ }^{78}$

\section{Patients and methods}

Twelve patients with hypertrophic obstructive cardiomyopathy, 12 with hypertrophic non-obstructive cardiomyopathy, eight with dilated (congestive) cardiomyopathy, and six with endocardial fibroelastosis, which is one of the allied diseases of cardiomyopathy, ${ }^{9}$ were included in this study. In all cases, the diagnosis was established on the basis of clinical investigations.

The specimens for histological examination were 
obtained from the left ventricular wall at necropsy in six cases, by surgical excision in two, and at biopsy in three and stained by Masson's trichrome stain.

\section{ECHOCARDIOGRAPHY}

The cross sectional echocardiograms were obtained by a sector scan along the long axis of the left ventricle at the fourth or fifth intercostal space. With a scan along the short axis of the ventricle, the ultrasonic beam frequently hit the hypertrophied ventricular wall obliquely. The image thus obtained was inadequate for measuring the echo intensity because of attenuation of the ultrasound due to the increased length of the pathway through the myocardium.

Echocardiography was carried out with the patient in the supine position using the proximity immersion method ${ }^{10}$ in synchronisation with cardiac pulsation within three months of the histological examination. A linear amplifier was used as a receiving amplifier for exact measurement of the echo intensity. The 3.5 $\mathrm{MHz}$ transducer used in this study had a concave disc with a diameter of $30 \mathrm{~mm}$ and a radius of curvature of $100 \mathrm{~mm}$. The ultrasonic beam was focused at a distance of 90 to $100 \mathrm{~mm}$ from the transducer. The width of the beam in the vicinity of the focus was less than 1.0 to $1.5 \mathrm{~mm}$. In a sector scan, the beam was focused on the posterior wall of the left ventricle.

Attenuation of the intensity of the ultrasound during propagation through the heart was compensated for by a sensitivity time control circuit. This circuit was adjusted so that the intensity of the chest wall echo became almost the same as that of the echoes outside the posterior ventricular wall (pleuropericardial echoes). For the evaluation of the echo pattern of the left ventricular wall, the gain setting of the receiving amplifier was set at an optimum level of about 25 to $30 \mathrm{~dB}$ higher than the standard level, at which no noise echoes occur in the left ventricular area.

In sensitivity graded paired echocardiography, ${ }^{78}$ six to eight images obtained by changing the gain setting of the receiving amplifier by 5 to $6 \mathrm{~dB}$ from the standard gain level were used for measuring the echo intensity. The intensity of the abnormal echoes in the endocardium and myocardium was measured in decibels by determining the difference between the gain level of the standard echo and the gain level at which the abnormal echoes emerged. In this way, the intensity of the abnormal echoes could be measured by interpolation with an accuracy of about $3 \mathrm{~dB}$.

The gain level at which pleuropericardial echoes emerged is used as a standard $(0 \mathrm{~dB})$ because $(a)$ the posterior aspect of the pericardium is close to the left ventricular wall, $(b)$ the pleuropericardial echoes are stronger than those of other cardiac structures, $(c)$ the pleuropericardial echoes can be recorded in all sub- jects examined, and $(d)$ in a sector scan along the long axis of the heart at the parasternal border in the fourth or fifth intercostal space, the pericardium is concave towards the chest wall. Usually the direction of the ultrasonic beam is almost perpendicular to the ventricular wall and pericardium except in cases of pericardial effusion.

The range of intensity of abnormal echoes was measured as the difference between the gain level of the strongest abnormal echoes and that of the weakest ones on the same plane of scan.

The echocardiographic findings were compared with the histological findings of specimens taken from the site that was closest to the area of the ultrasound image.

\section{Results}

\section{LEFT VENTRICULAR WALL ECHOES}

On the echocardiograms obtained at the optimum gain level, abnormal echoes that were absent in normal subjects were seen in the area of the left ventricular wall in patients with cardiomyopathy. Table 1 summarises the echo findings in all patients, which are classified according to the type of echo.

The abnormal echoes were classified into three types (Fig. 1).

Type I-Very strong wide homogeneous (band shape) echoes were present at the endocardium and subjacent myocardium (Fig. 1a).

Type II-Strong irregular echoes were localised in the inner half of the myocardium subjacent to the endocardium (Fig. 1b).

Type III-Freckle-like echoes were distributed evenly or unevenly throughout the myocardium (Fig. 1c). The type III echoes were further classified into three subtypes (Fig. 2): (a) inhomogeneous large freckle-like echoes (Fig. 2a), (b) scattered homogeneous, medium sized, freckle-like echoes which occasionally appear in a reticular pattern (Fig. 2b), and $(c)$ micronodular or inhomogeneous powdery echoes (Fig. 2c). Echoes similar to the powdery echoes of type III-3 are frequently seen in normal hearts. Occasionally it is difficult to differentiate echoes of type III-3 from powdery echoes in normal hearts on the basis of their echo characteristics.

\section{CORRELATION BETWEEN ECHO TYPES AND HISTOLOGICAL FINDINGS}

Patients with similar echocardiographic characteristics had similar histological findings. In patients with type II echoes pronounced degeneration and an increase in fibrous tissue in the endacardium and diffuse or focal fibrosis in the inner half of the left ventricular wall were seen.

The type II echo was found to be intermediate be- 
Table 1 Echocardiographic findings in relation to clinical diagnosis

\begin{tabular}{|c|c|c|c|c|c|c|c|}
\hline Case & $\begin{array}{l}\text { Age } \\
(y r)\end{array}$ & Sex & Diagnosis & Echo type & $\begin{array}{l}\text { Echo intensity } \\
(d B)\end{array}$ & $\begin{array}{l}\text { Echo intensity } \\
\text { ranget }(d B)\end{array}$ & Addendum \\
\hline $\begin{array}{r}1 \\
2 \\
3 \\
4 \\
5 \\
6 \\
7 \\
8 \\
9 \\
10 \\
11 \\
12 \\
13 \\
14 \\
15 \\
16 \\
17 \\
18 \\
19 \\
20 \\
21 \\
22 \\
23 \\
24 \\
25 \\
26 \\
27 \\
28 \\
29 \\
30 \\
31\end{array}$ & $\begin{array}{r}46 \\
20 \\
23 \\
22 \\
32 \\
35 \\
40 \\
27 \\
1 \\
4 \\
5 \\
6 \\
3 \\
4 \\
50 \\
44 \\
72 \\
32 \\
20 \\
26 \\
37 \\
21 \\
25 \\
41 \\
23 \\
23 \\
16 \\
31 \\
39 \\
48 \\
16\end{array}$ & $\begin{array}{l}F \\
M \\
F \\
F \\
F \\
M \\
M \\
M \\
F \\
M \\
M \\
F \\
F \\
M \\
M \\
M \\
M \\
F \\
F \\
M \\
M \\
F \\
M \\
F \\
M \\
M \\
M \\
M \\
M \\
M \\
M\end{array}$ & $\begin{array}{l}\text { COCM } \\
\text { COCM } \\
\text { COCM } \\
\text { COCM } \\
\text { COCM } \\
\text { COCM } \\
\text { COCM } \\
\text { COCM } \\
\text { EFE } \\
\text { EFE } \\
\text { EFE } \\
\text { EFE } \\
\text { EFE } \\
\text { EFE } \\
\text { HCM } \\
\text { HCM } \\
\text { HCM } \\
\text { HCM } \\
\text { HCM } \\
\text { HCM } \\
\text { HCM } \\
\text { HCM } \\
\text { HCM } \\
\text { HCM } \\
\text { HCM } \\
\text { HCM } \\
\text { HOCM } \\
\text { HOCM } \\
\text { HOCM } \\
\text { HOCM } \\
\text { HOCM }\end{array}$ & $\begin{array}{l}\text { III-1 } \\
\text { I } \\
\text { II } \\
\text { III-2 } \\
\text { III-2 } \\
\text { III-3 } \\
\text { I } \\
\text { III-1 } \\
\text { I } \\
\text { II } \\
\text { II } \\
\text { I } \\
\text { III-2 } \\
\text { II } \\
\text { III-3 } \\
\text { II } \\
\text { III-1 } \\
\text { III-3 } \\
\text { II } \\
\text { III-2 } \\
\text { III-3 } \\
\text { III-2 } \\
\text { III-1 } \\
\text { III-1 } \\
\text { II } \\
\text { III-3 } \\
\text { II } \\
\text { II } \\
\text { III-3 } \\
\text { III-3 } \\
\text { III-2 }\end{array}$ & $\begin{array}{r}10 \\
5 \\
20 \\
18 \\
20 \\
25 \\
10 \\
15 \\
5 \\
15 \\
18 \\
15 \\
20 \\
15 \\
24 \\
15 \\
6 \\
30 \\
24 \\
25 \\
25 \\
12 \\
10 \\
5 \\
15 \\
30 \\
15 \\
24 \\
30 \\
25 \\
20\end{array}$ & $\begin{array}{r}5 \\
5 \\
0 \\
10 \\
5 \\
5 \\
5 \\
10 \\
3 \\
0 \\
6 \\
5 \\
5 \\
10 \\
5 \\
15 \\
10 \\
0 \\
5 \\
15 \\
0 \\
5 \\
15 \\
20 \\
10 \\
5 \\
10 \\
5 \\
0 \\
5 \\
15\end{array}$ & $\begin{array}{l}\text { Postpartum (necropsy) } \\
\text { (Biopsy) } \\
\text { (Necropsy) } \\
\text { (Necropsy) } \\
\text { (Necropsy) } \\
\text { Nephrosis (necropsy) } \\
\text { (Biopsy) } \\
\text { Nephrosis } \\
\text { (Biopsy) Asymmetric (-), septal hypertrophy } \\
\text { Asymmetric (+), septal hypertrophy } \\
\text { Asymmetric (-), apical hypertrophy } \\
\text { Asymmetric (-), diffuse hypertrophy } \\
\text { Asymmetric (+), septal hypertrophy } \\
\text { (biopsy) }\end{array}$ \\
\hline $\begin{array}{l}32 \\
33 \\
34\end{array}$ & $\begin{array}{l}40 \\
35 \\
37\end{array}$ & $\begin{array}{l}\mathbf{M} \\
\mathbf{M} \\
\mathbf{F}\end{array}$ & $\begin{array}{l}\text { HOCM } \\
\text { HOCM } \\
\text { HOCM }\end{array}$ & $\begin{array}{l}\text { II } \\
\text { III-2 } \\
\text { III-2 }\end{array}$ & $\begin{array}{l}20 \\
25 \\
20\end{array}$ & $\begin{array}{r}10 \\
5 \\
5\end{array}$ & $\begin{array}{l}\text { Asymmetric (+), septal hypertrophy } \\
\text { Asymmetric (+), septal hypertrophy } \\
\text { Asymmetric (-), diffuse hypertrophy } \\
\text { (necropsy) }\end{array}$ \\
\hline $\begin{array}{l}35 \\
36 \\
37\end{array}$ & $\begin{array}{l}46 \\
49 \\
39\end{array}$ & $\begin{array}{l}\mathbf{F} \\
\mathbf{M} \\
\mathbf{M}\end{array}$ & $\begin{array}{l}\text { HOCM } \\
\text { HOCM } \\
\text { HOCM }\end{array}$ & $\begin{array}{l}\text { III-2 } \\
\text { II } \\
\text { II }\end{array}$ & $\begin{array}{l}15 \\
15 \\
20\end{array}$ & $\begin{array}{r}15 \\
15 \\
5\end{array}$ & $\begin{array}{l}\text { Asymmetric (+), diffuse hypertrophy } \\
\text { Asymmetric (+), apical hypertrophy } \\
\text { Asymmetric (+), septal hypertrophy } \\
\text { (biopsy) }\end{array}$ \\
\hline 38 & 13 & $\mathbf{M}$ & HOCM & II & 24 & 0 & Asymmetric (+), septal hypertrophy \\
\hline
\end{tabular}

*Gain setting of the receiving amplifier when abnormal echoes emerge.

†Difference between the gain level of the strongest abnormal echoes and that of the weakest ones.

COCM, congestive cardiomyopathy; EFE, endocardial fibroelastosis; HCM, hypertrophic non-obstructive cardiomyopathy; HOCM, hypertropic obstructive cardiomyopathy.

tween types I and III as regards echocardiographic and histological findings except for differences in the distribution of fibrous tissue. The results from patients with type II echoes are therefore not given. Only the findings of representative cases with type I and type III echoes are given.

Type I echoes (Fig. 3, case 7)

A strong wide echo was present in the endocardium and subjacent myocardium (Fig. 3a); the margin of the endocardial echo was relatively smooth. Strong homogeneous echoes were detected in the myocardium by a slight increase in the gain setting of the amplifier (Figs. 3b and 3c); the endocardium was relatively smooth, and the sites of pronounced degeneration and an increase in fibrous tissue were evident in the endocardium and the surviving myocardial tissue. Degeneration and fibrosis of the myocardial tissue adjacent to the epicardium were, however, less pro- nounced than those of the myocardium subjacent to the endocardium (Figs. 3d and 3e).

Type III-1 echoes (Fig. 4, case 17)

Inhomogeneous strong, large, freckle-like echoes were present in the myocardium (Fig. 4). In this patient (case 17), wide strong echoes were evident in the basal to mid portion of the endocardium. Usually the abnormal echoes of type III-1 can be seen as inhomogeneous spotted echoes by decreasing the gain setting of the amplifier (see also Fig. 9). In the endocardium and subjacent myocardium, the thick fibrous tissue can be seen as a band that is stained blue. Focal degeneration and diffuse fibrotic changes were present at the sites where strong inhomogeneous freckle-like echoes were visible (Fig. 4c). At the midportion, an increase in striped fibrous tissue could be seen in the myocardium, in particular, adjacent to the endocardium (Fig. 4d). An increase in the lattice pat- 


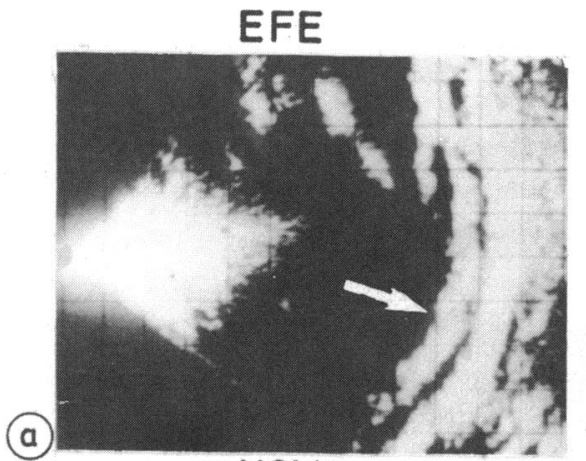

(a)

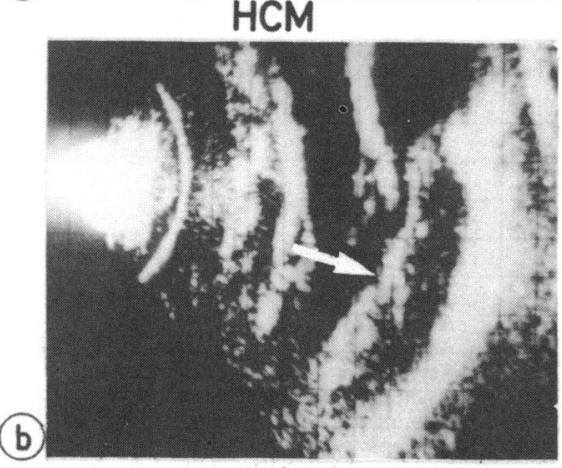

$\mathrm{HCM}$

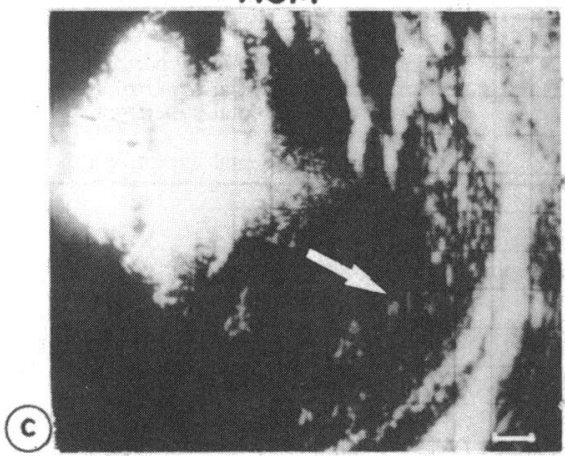

tern of the interstitial fibrous tissue throughout the myocardium was also evident. Thus the wide strong (band-shaped) echo in the endocardium was caused by the presence of fibrotic tissue in the endocardium or in the subjacent myocardium (Figs. 3 and 4)

Type III-2 echoes (Fig. 5, case 34)

The echo of the endocardium was rather weak (Fig. 5). Medium sized freckle-like echoes were visible in the myocardium of the left ventricular wall (Figs. 5a and 5b; see also Fig. 10). Histological examination showed a slight increase in fibrous tissue in the endocardium, as evidenced by the scattered small areas that were stained blue throughout the myocardium (Fig. 5c). The areas of degeneration,

\section{COCM}

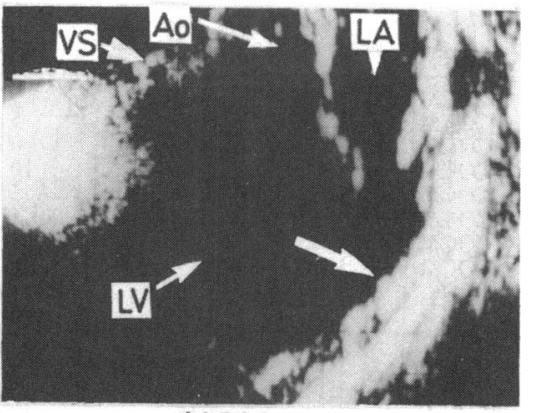

$\mathrm{HCM}$

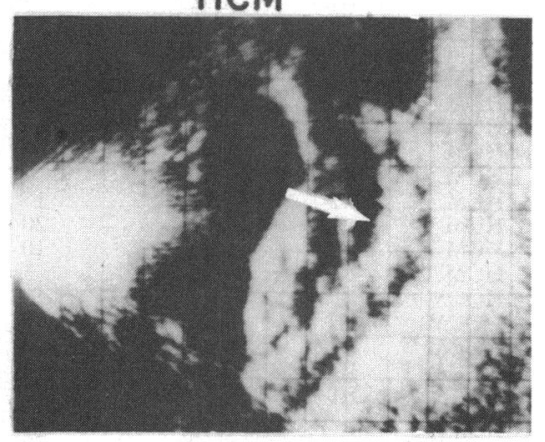

COCM

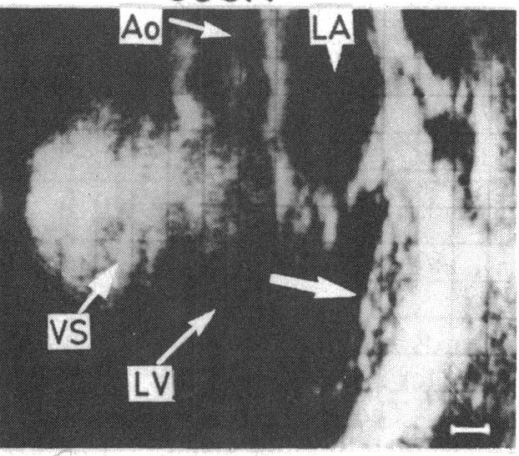

small to medium in size, were scattered throughout the myocardium. There was an increase in the lattice pattern of fibrous tissue as shown in Fig. 6.

These results suggest that strong freckle-like echoes of uneven distribution occur as the result of focal degeneration or a diffuse increase in fibrous tissue in the myocardium and that the medium sized echoes occur as the result of an increase in the lattice pattern of interstitial fibrous tissue.

Type III-3 echoes (Fig. 7, case 26)

The left ventricular wall and the septum were thicker than normal. Despite a slight increase in the intensity of the endocardial echo, there were powdery echoes in the left ventricular wall (Fig. 7a). When the gain set- 


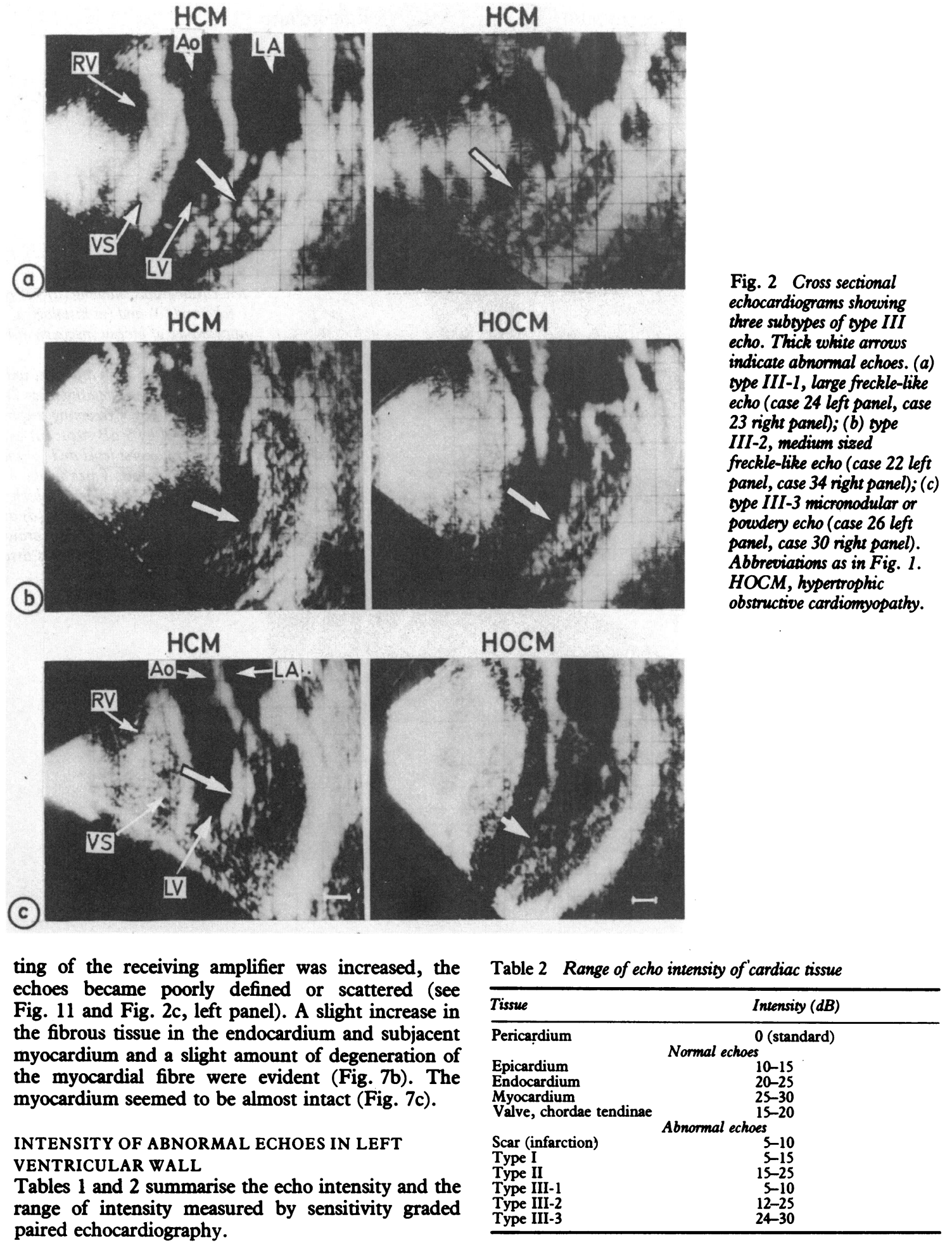



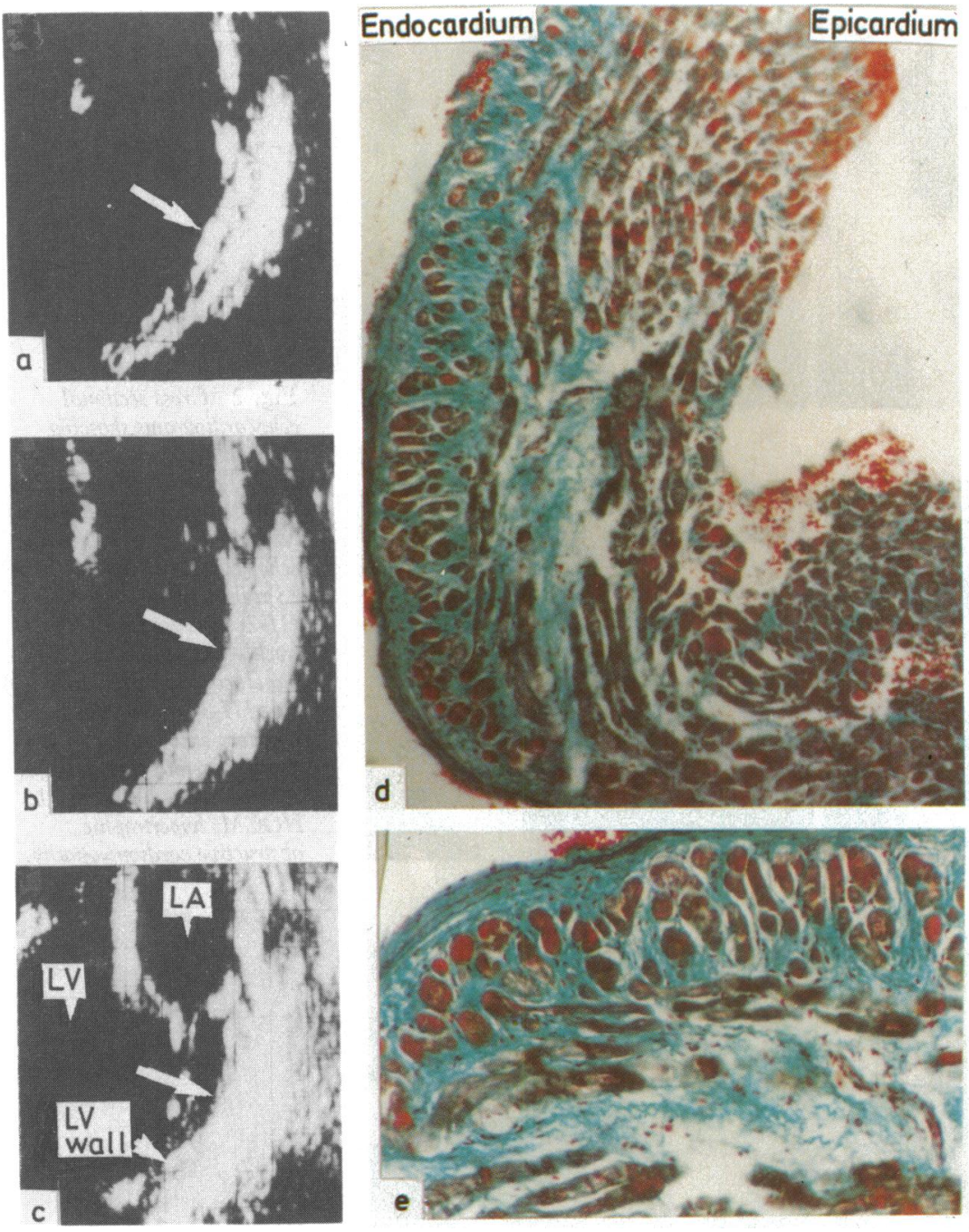

Fig. 3 Cross sectional echocardiograms showing $(a)-(c)$ type $I$ echo and $(d)$ and (e) histological appearance of biopsy specimen of the endomyocardium of the left ventricular wall from a patient with congestive cardiomyopathy (case 7). The gain setting of receiving amplifier was changed by $5 \mathrm{~dB}$ steps: (a) was taken at the lowest level and $(b)$ and (c) at higher levels. Thick white arrows show the areas from which biopsy specimens were taken. (d) and (e) show degeneration of myocardial fibre and an increase in fibrous tissue in the myocardium near the endocardium stained blue.
Type I and type III-I echoes The intensity of abnormal echoes in the endocardium and myocardium was greatly increased (Figs. 8 and 9). With the gain setting of the amplifier increased slightly, continuous (type I) or large freckle-like (type III-1) echoes were present in the endocardium and myocardium. These abnormal echoes emerged at a level of 5-15 dB and were about 10-25 dB stronger than normal endocardial or myocardial echoes.

Type II and type III-2 echoes (Fig. 10).

The medium sized freckle-like echoes were at a level of about 12 to $25 \mathrm{db}$ (more than about 5 to $15 \mathrm{~dB}$ stronger than normal myocardial echoes).

Type III-3 echoes (Fig. 11)

Powdery echoes, the margin of which is poorly defined, emerged at a level of about 25 to $30 \mathrm{~dB}$. The intensity of these echoes was within normal range.

Intensity range of abnormal echoes (Table 1)

The types I and III-3 echoes were in the narrow range of intensity $(0-5 \mathrm{~dB})$. The types II, III-1, and III-2 echoes were either in a narrow $(0-5 \mathrm{~dB})$ or a wide range (10-15 dB). 


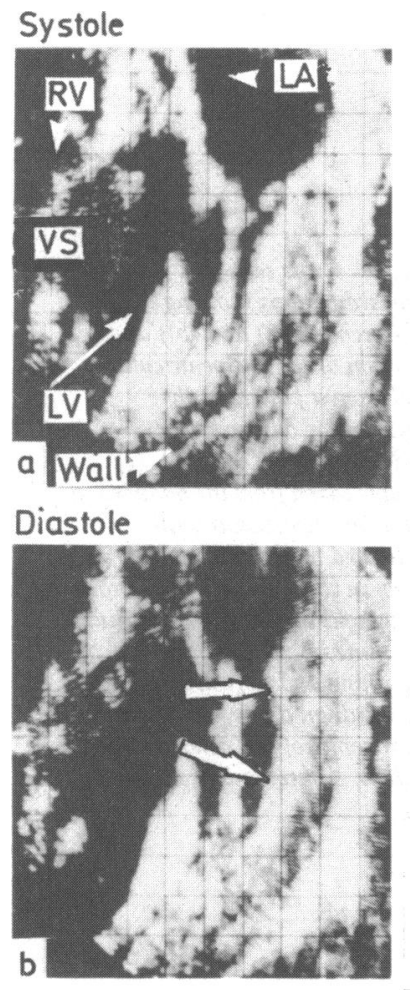

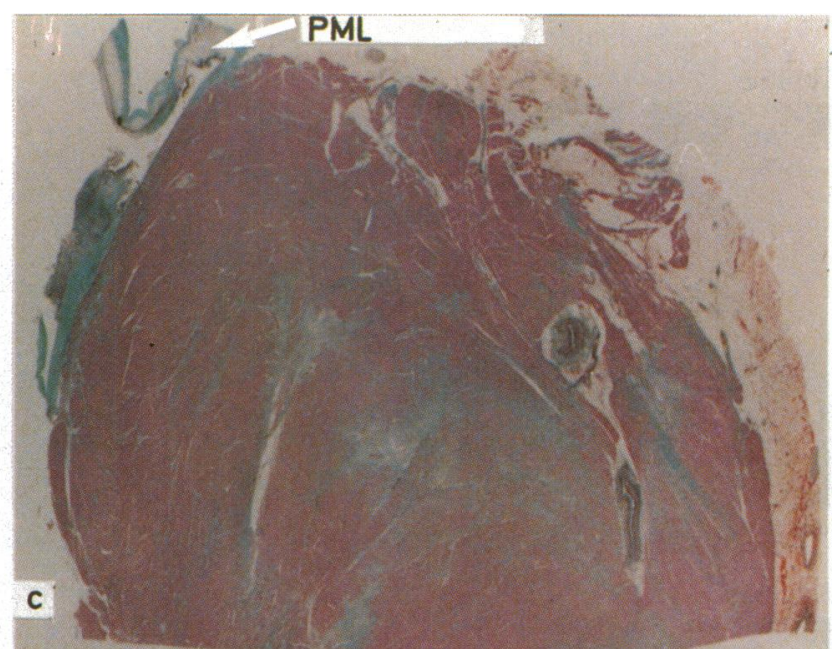
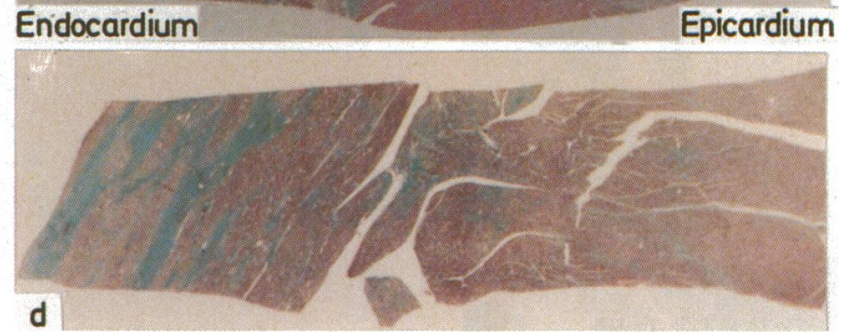

Fig. 4 Cross sectional echocardiograms showing type III-I echoes $((a)$ and $(b))$ and histological sections of the left ventricular wall $((c)$ and $(d))$ (case 17). (c) Sample taken from the basal portion as indicated by the thin white arrow on the echocardiogram (b). (d) Sample taken from the midportion of the left ventricular wall as indicated by the thick white arrow on the echocardiogram $(b)$. Thickening of the endocardium, diffuse myocardial degeneration, and focal fibrosis are found throughout the myocardium of the basal portion. At the midportion of the ventricle band-like and scattered fibrosis throughout the myocardium are stained blue. Abbreviations as in Fig. 1. PML, posterior mitral leaflet.

\section{Discussion}

Thickening of the endocardium in association with subendocardial fibrosis, hypertrophy of cardiac muscle cells, and diffuse or focal interstitial fibrosis of the ventricular wall are the common histopathological findings in cardiomyopathy. ${ }^{11-13}$ Irregular arrangements of cardiac muscle cells, degeneration, and pronounced fibrosis of the ventricular septum are frequently seen in hypertrophic cardiomyopathy. ${ }^{14-16}$ Accordingly, a non-invasive method of evaluating the changes, as mentioned above, when established will allow a more exact and less laborious estimation of the severity of a cardiomyopathy. For this reason, attempts have been made to apply a well focused ultrasound.

According to the principle of pulse reflection (echocardiography), the occurrence of abnormal echoes as mentioned above strongly suggests that tissue with acoustic characteristics different from those of normal tissues is present and that acoustic boundaries are formed around areas where the abnormal echoes are detected.

To confirm the presence of abnormal tissue the echocardiographic findings were analysed with reference to the histological findings of specimens taken at necropsy or biopsy. As already described, degeneration or fibrosis was present in the endocardium or myocardium at sites where abnormal echoes were detected.

Changes in echo pattern are caused by changes in the acoustic properties of tissue ${ }^{17} 18$ and by changes in the size and spatial arrangement of acoustic boundary surfaces and also by machine characteristics.

When the electric circuits, such as a differential circuit and an automatic gain control circuit, are used 

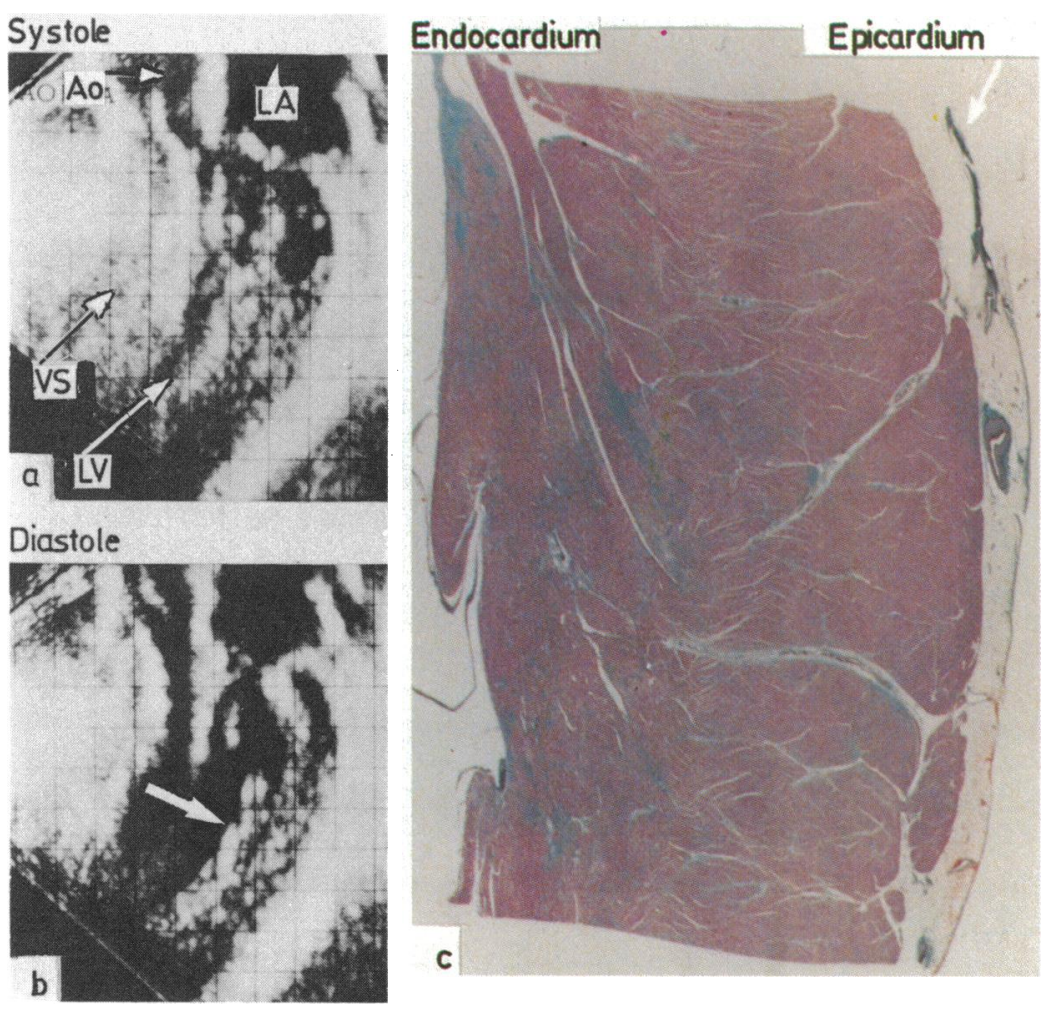

Fig. 5 Cross sectional echocardiograms showing type III-2 echoes ((a) and (b)) and (c) a section of the left ventricular wall from a patient with hypertrophic obstructive cardiomyopathy (case 34). (c). Sample taken from the midportion of the left ventricular wall (indicated by the thick white arrow in (b)). The sites of fibrosis throughout the entire myocardium are stained blue. A slight thickening and fibrosis of the endocardium and symmetrical hypertrophy of the ventricle are evident. Abbreviations as in Fig. 1. to modify the echo signals that are received, so as to make images sharper, this will have a notable effect on the intensity and pattern of echoes. The use of apparatus equipped with modifying circuits like those of a commercial machine will, therefore, be inadequate for the quantitative evaluation of the intensity and echo characteristics. In this study, we paid special attention to the machine's characteristics by installing various devices, such as concave transducers with a large diameter for obtaining sharp directivity and high resolution at the target area, a linear amplifier as the receiver for the exact measurement of differences in intensity of the echo, and an STC circuit for the compensation of ultrasonic attenuation during propagation of the ultrasound. In this study, therefore, the differences in acoustic characteristics of the endomyocardial tissues were clearly distinguished, and the extent and pattern of distribution of degeneration or fibrosis in the myocardium were faithfully reflected by the echo patterns.

Nevertheless, the echo patterns of echocardiograms do not always coincide with the pattern of distribution of fibrous tissue on histological specimens, presumably because: $(a)$ the direction of the planes along which the scans were taken does not always exactly coincide with that of the histological sections, $(b)$ the resolution of the echocardiograms is weaker than that of light microscopy, and $(c)$ histology of the stained specimens shows the distribution of optical dielectric permittivity of the excised tissue, whereas the results obtained by ultrasonic methods show the distribution in vivo of elastic properties.

The propagation of ultrasound through biological tissues is influenced by changes in the three dimensional microscopic structure of the tissue. ${ }^{19} 20$ Accordingly, ultrasound may be reflected from abnormal tissue and its surroundings in a different way from normal tissue. ${ }^{19}$ Thus changes in the microscopic structure of the tissue within the ultrasonic beam width will be reflected on to the echocardiogram despite the poorer resolution of echocardiography than of light microscopy.

The occurrence of echoes of type I indicates therefore the presence of fibrotic changes in a fairly large area of the endocardium and its surroundings, that of the echoes of type II the presence of fibrotic thickening of the endocardium and focal degeneration or fibrotic changes scattered in the myocardium sub- 


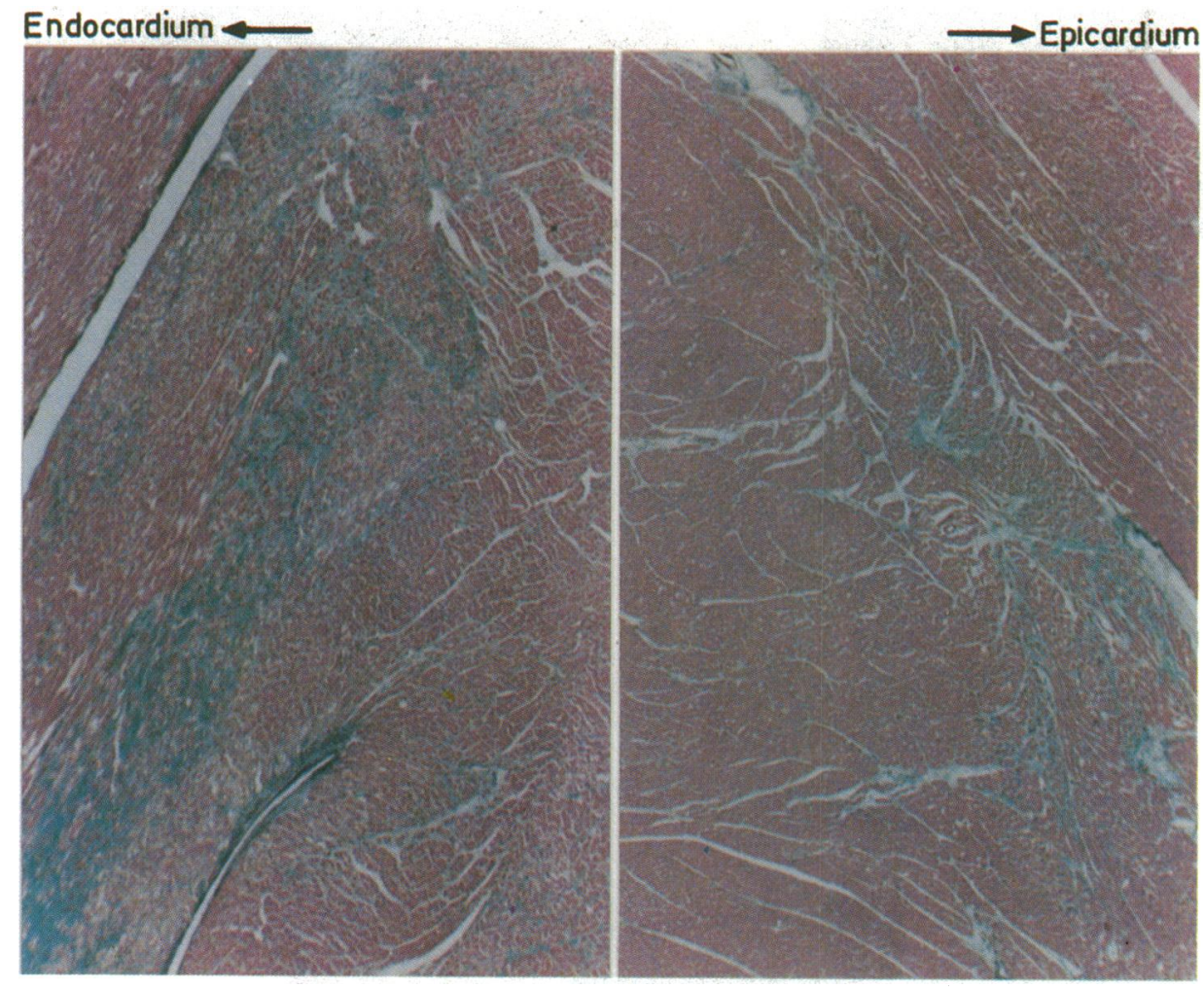

Fig. 6 Histological appearance of the same section as in Fig. 5 at higher magnification. Sites of fibrosis are stained blue. $(\times 40)$

jacent to the endocardium, and that of the echoes of type III the presence of focal degeneration and diffuse fibrotic changes throughout the myocardium.

Nevertheless, in one patient (case 8) with type III-1 echoes, intertrabecular microthrombi in association with diffuse fibrotic tissue were found at the sites where strong inhomogeneous freckle-like echoes were visible (Fig. 12). The data from this patient suggested that not only scattered focal degeneration and diffuse fibrosis but also organised microthrombi within the dilated trabecular space would give rise to strong large freckle-like echoes in the myocardium.

On the other hand, in sensitivity graded paired echocardiography the types I and III-1 echoes were strongest, followed by types II and III-2 echoes and type III- 3 echoes. Abnormal echoes reflected from the site of fibrotic tissue in the endocardium and myocardium of the left ventricle are about 5-20 dB stronger than those from normal tissue (Table 2).

As shown in Table 1, the intensity of types II and III-2 echoes ranged from $15 \mathrm{~dB}$ (strong echoes) to $25 \mathrm{~dB}$ (weak echoes) in contrast to the narrow intensity range of type I and III-3 echoes. The type II, III- 1 , and III- 2 echoes could be classified into those with a wide range and those with a narrow range of intensity. The occurrence of echoes with a wide range indicated that abnormal echoes increased in number in proportion to the increase in the gain setting of the receiving amplifier and that the echoes with various levels of intensity (from about $10 \mathrm{~dB}-20 \mathrm{~dB}$ ) could be found in the same patient (case 23, Fig. 9). The occurrence of echoes within a narrow range of inten- 

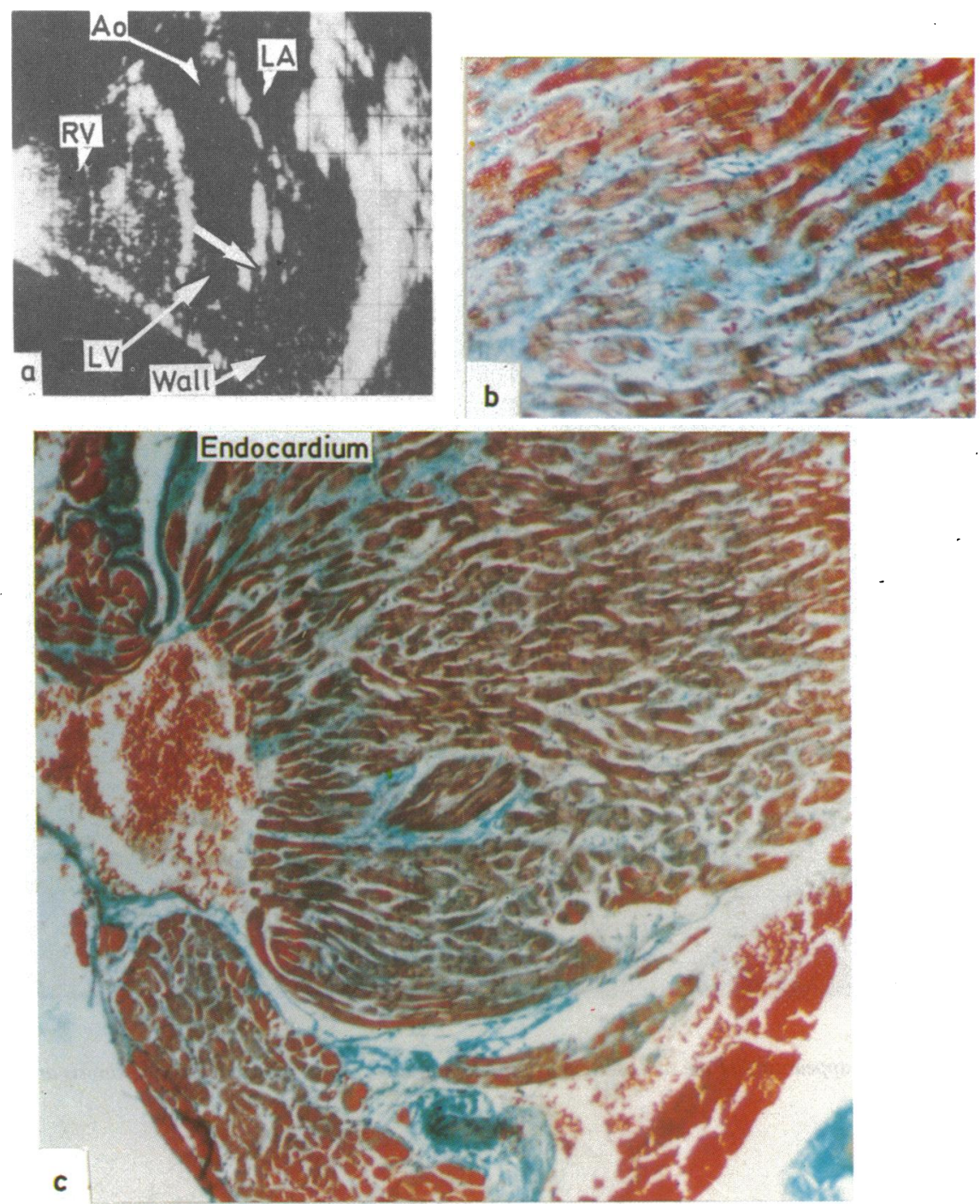

Fig. 7 (a) Cross sectional echocardiograms showing type III-3 echoes and ( $b$ and $c$ ) a histological section of a biopsy specimen taken from a patient with hypertrophic cardiomyopathy (case 26), from the site shown by the thick white atrow in (a). (b) Shows the same specimen at a higher magnification. A slight increase infibrous tissue and degeneration are seen; only a few musclefibres are affected by degenerative changes.

sity indicated that almost all abnormal echoes in the myocardium emerged with a slight increase in the gain setting of the amplifier and that the intensity level of abnormal echoes was within a certain gain level (Fig. 10). The area of strong echoes $(5-10 \mathrm{~dB})$ corresponded to the area of massive degeneration or pronounced increase in fibrous tissue (Fig. 4a). The area of weak echoes (15-20 dB) corresponded to the site of degeneration or a slight increase in fibrous tissue (Fig. 5b).

The echo intensity depends on the difference in acoustic impedance with a pulsed ultrasonic beam passing from one tissue to the next and on the size and configuration of the boundary surface. The charac- 

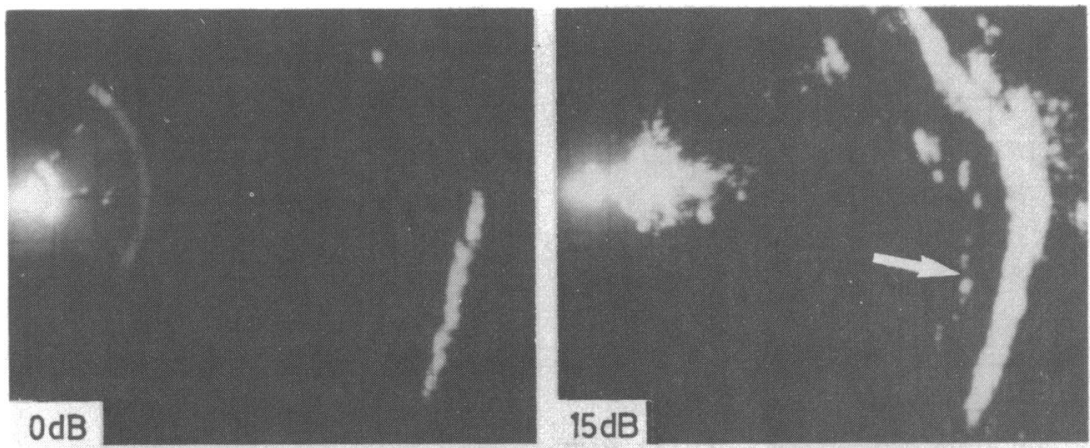

teristic acoustic impedance $(\mathbf{z})$ of a medium is defined by the equation:

$$
\mathrm{z}=\sqrt{\mathrm{k} \cdot \rho}
$$

The magnitude of ultrasonic reflection, as shown by reflection coefficient $(r)$, is related to the density and elasticity of the tissues

$$
r=\frac{z_{2}-z_{1}}{z_{2}+z_{1}}
$$

where $\mathbf{k}$ is the bulk modulus of elasticity, $\rho$ the density of the medium, and $z_{1}$ and $z_{2}$ respectively the characteristic acoustic impedance of the tissue on both sides of the acoustic boundary.
Fig. 8 Sensitivity graded paired echocardiograms of a patient with endocardial fibroelastosis (case 9). The gain setting of the receiving amplifier was increased in $6 \mathrm{~dB}$ steps. Intensified abnormal endocardial echoes emerge at a level of $12 \mathrm{~dB}$ (thick white arrows).
When the structure of the myocardium is affected by destructive changes at a microscopic level, as in tissue degeneration, the boundaries between myocardial fibres within the myocardium may disappear. Then the heterogeneous acoustical medium of the myocardial tissue may become almost homogeneous. Elasticity or stiffness of the diseased tissue becomes different from that of normal tissue when degeneration or fibrotic change occurs in the myocardium. Thus a change in acoustic characteristics and density of the myocardial tissue occurs in association with the destruction of the microscopic structure of the myocardium. 171821

Furthermore, an increase in the consistency or 

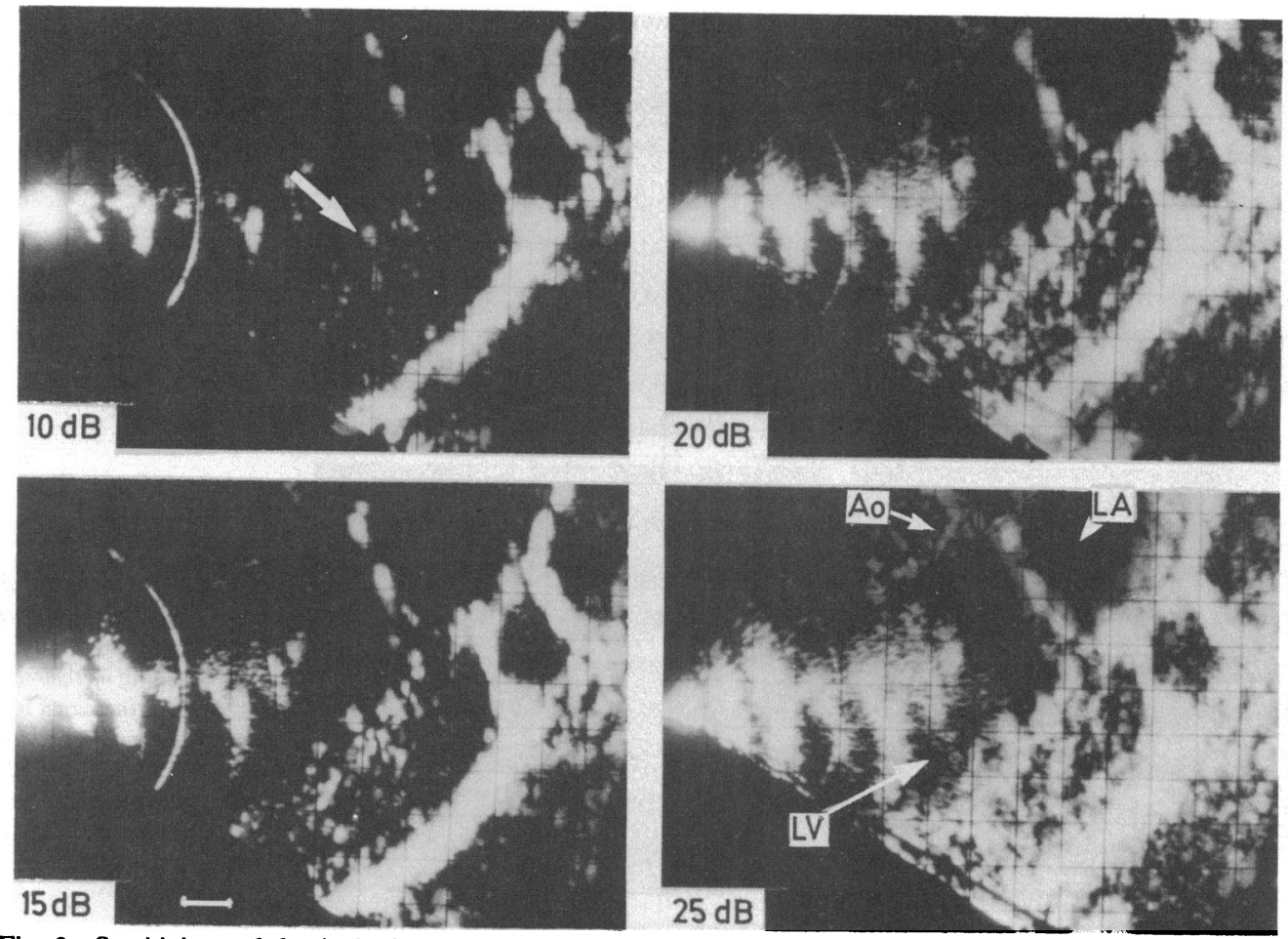

Fig. 9 Sensitivity graded paired echocardiograms from a patient with hypertrophic cardiomyopathy (case 23).

Inhomogeneous large freckle-like echoes (type III-1) in the myocardium emerge at a level of $10 \mathrm{~dB}$ (thick white arrow). Echoes at various levels of intensity are detected by increasing the gain setting of the amplifier. Abnormal echoes are seen in $a$ wide range of intensity $(15 \mathrm{~dB})$.

density of the site of degeneration or fibrosis might be correlated with the collagen content of the tissue, as exemplified by the scar of myocardial infarction. ${ }^{182122}$ An increase in collagen content causes also an increase in the intensity of the echoes ${ }^{22-24}$ that are reflected from the interface between the site of degeneration or fibrosis and normal tissue.

Thus the boundary between the normal myocardium and the area of degeneration or of fibrosis probably serves as a source of echoes, and a change in the intensity of echoes in the left ventricular wall and the intensity of the abnormal echoes are closely related to the consistency and density of the degenerated or fibrotic tissue. 46

Thus the types II and III-2 echoes include echoes from hard or tight fibrous tissue and from soft or loose fibrous tissue. The echoes with a wide intensity range are from fibrous tissue of differing consistency. The abnormal echoes with a narrow range of intensity are from the uniformly diseased area with a similar consistency.
The problem relating to scattering and interference among echoes within biological tissues remains to be solved. Nevertheless, the large strong echoes indicate the presence of tight or massive fibrous tissue and the moderate or small weak echoes that of loose or patchy fibrous tissue in the myocardium. The difference in intensity of the echoes thus probably reflects the differences in the consistency or density of the site of degeneration or fibrosis of the myocardium.

When an ultrasonic beam was focused on the septum, echoes similar to those from the left ventricular wall were also found (data not shown). Usually abnormal freckle-like echoes on the septum are present in the early stages of hypertrophic cardiomyopathy or hypertrophic obstructive cardiomyopathy before abnormal echoes are evident in the ventricular free wall. Such findings in patients with cardiomyopathy suggest that the changes in the septum precede those in the free wall.

In conclusion, the endomyocardial damage of the left ventricular wall in cardiomyopathy can be 

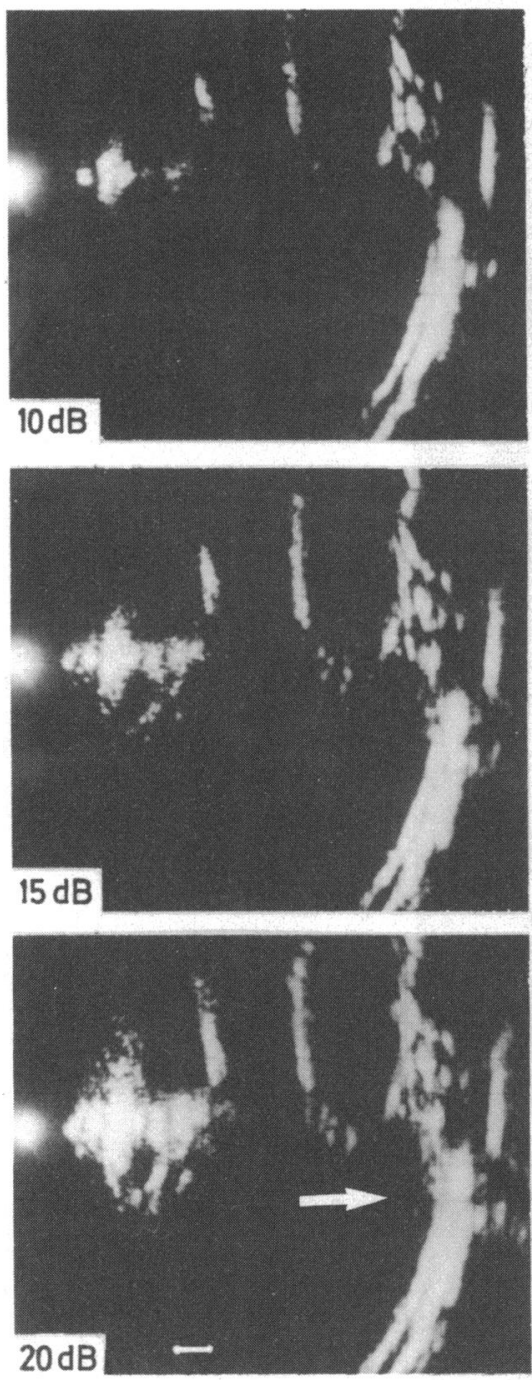

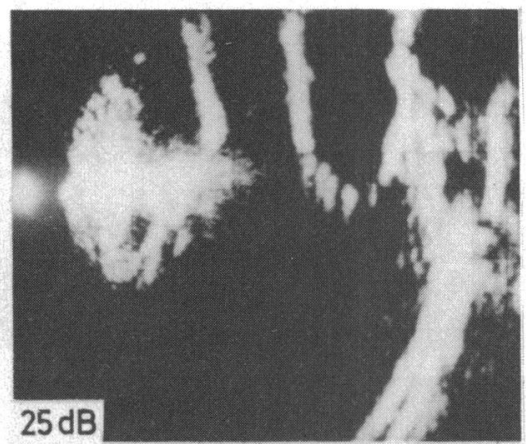

Fig. 10 Sensitivity graded paired echocardiograms from a patient with

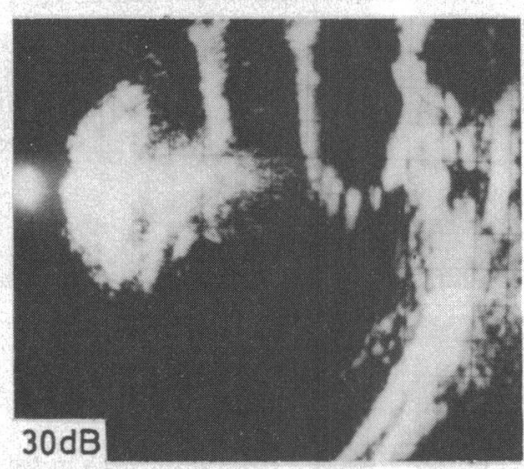
congestive cardiomyopathy (case 5). Almost homogeneous and medium sized freckle-like echoes (type III-2) are seen throughout the myocardium of the left ventricular wall. Abnormal echoes emerge at a level of $20 \mathrm{~dB}$ (thick white arrow). Almost all the abnormal echoes are already evident at a level of $25 \mathrm{~dB}$. The number of abnormal echoes remained unchanged, even when the gain setting of the amplifier was increased. Thus the intensity of the abnormal echoes was in a narrow range $(5 \mathrm{~dB})$.

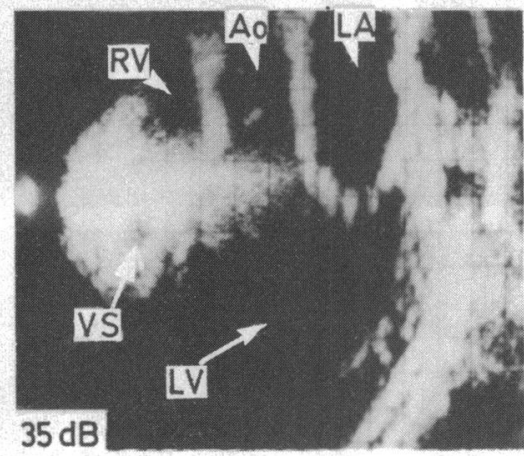

detected non-invasively by means of ultrasound. The extent, the pattern of distribution, and the consistency of the site of degeneration or fibrosis of the myocardium can be estimated by analysing the echo pattern and the echo intensity.

We thank Drs Ito, Nagashima and Shinoda, Sendai City Hospital, for allowing us to report on their patients and their biopsy specimens, and Professor F Dunn, Bioacoustics Research Laboratory, University of Illinois, for his advice on acoustical tissue characterisation of heart tissue.
This study was carried out by grant in aid for scientific research in 1979 to 1983 from the Ministry of Education, Science, and Culture of Japan.

\section{References}

1 Tanaka M, Neyazaki T, Kosaka S, et al. Ultrasonic evaluation of anatomical abnormalities of heart in cöngenital and acquired heart diseases. Br Heart $\mathcal{F}$ 1971; 33: 686-98.

2 Tanaka M. Evaluation of myocardial lesions by means of ultrasonocardiotomography. Myakuha 1975; 5: 196-202. [In Japanese] 

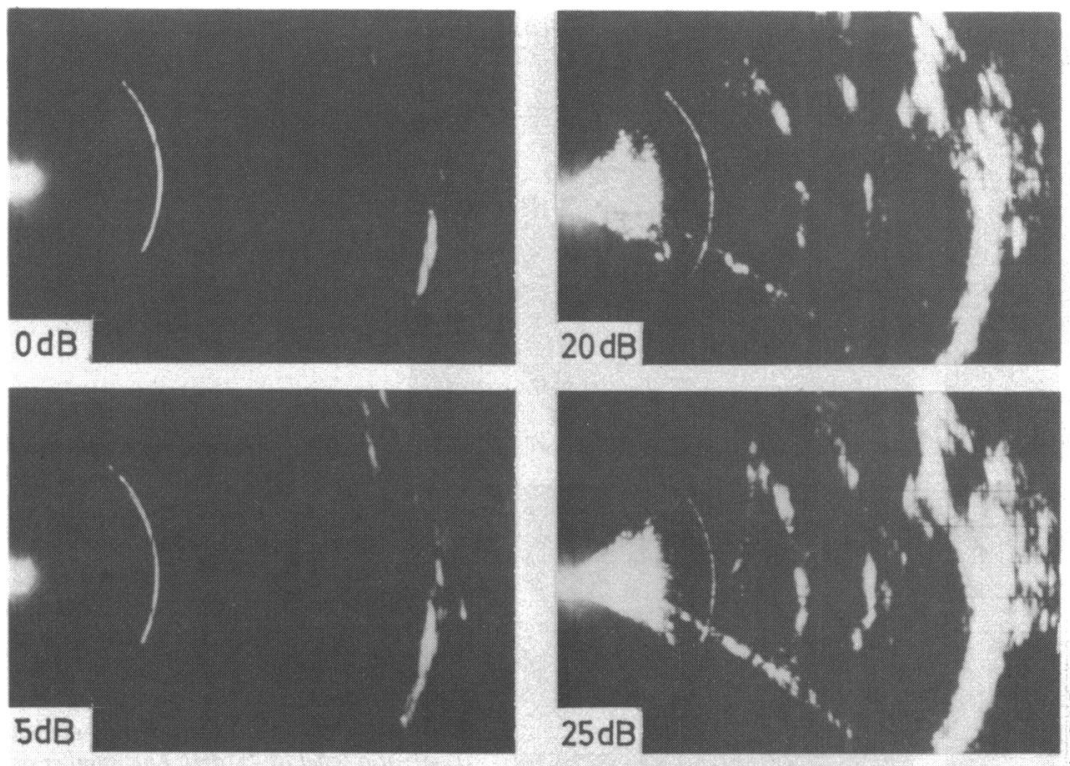

Fig. 11 Sensitivity graded paired echocardiograms from a patient with hypertrophic cardiomyopathy (case
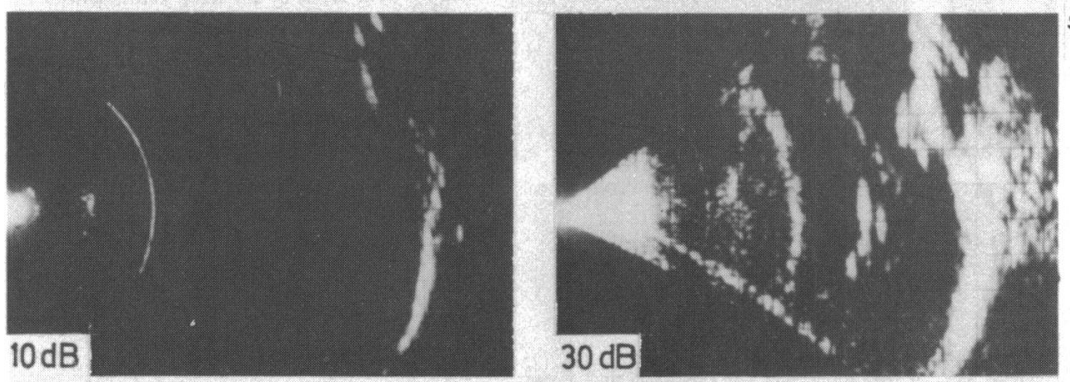
26). Powdery echoes (type III-3) are

3 Tanaka M, Terasawa Y, Hikichi H. Qualitative evaluation of the heart tissue by ultrasound. $\mathcal{F}$ Cardiogr 1977; 7: 515-30.

4 Tanaka M, Terasawa Y. Echocardiography: evaluation of the tissue character in myocardium. F pn Circ $\mathcal{F} 1979$; 43: 367-76.

5 Tanaka $M$. Tissue characterization of the heart. In: Wagai T, Omoto R, eds. Proceedings of the second meeting of the World Federation for Ultrasound in Medicine and Biology. Miyazaki: World Federation for Ultrasound in Medicine and Biology, 1979: 30-3. (International congress series; No 505. Amsterdam: Excerpta Medica.)

6 Hikichi . H, Tanaka M. Ultrasono-cardiotomographic evaluation of histological changes in myocardial infarction. Fpn Heart f 1981; 22: 287-98.

7 Kikuchi $Y$. Way to quantitative examination in 

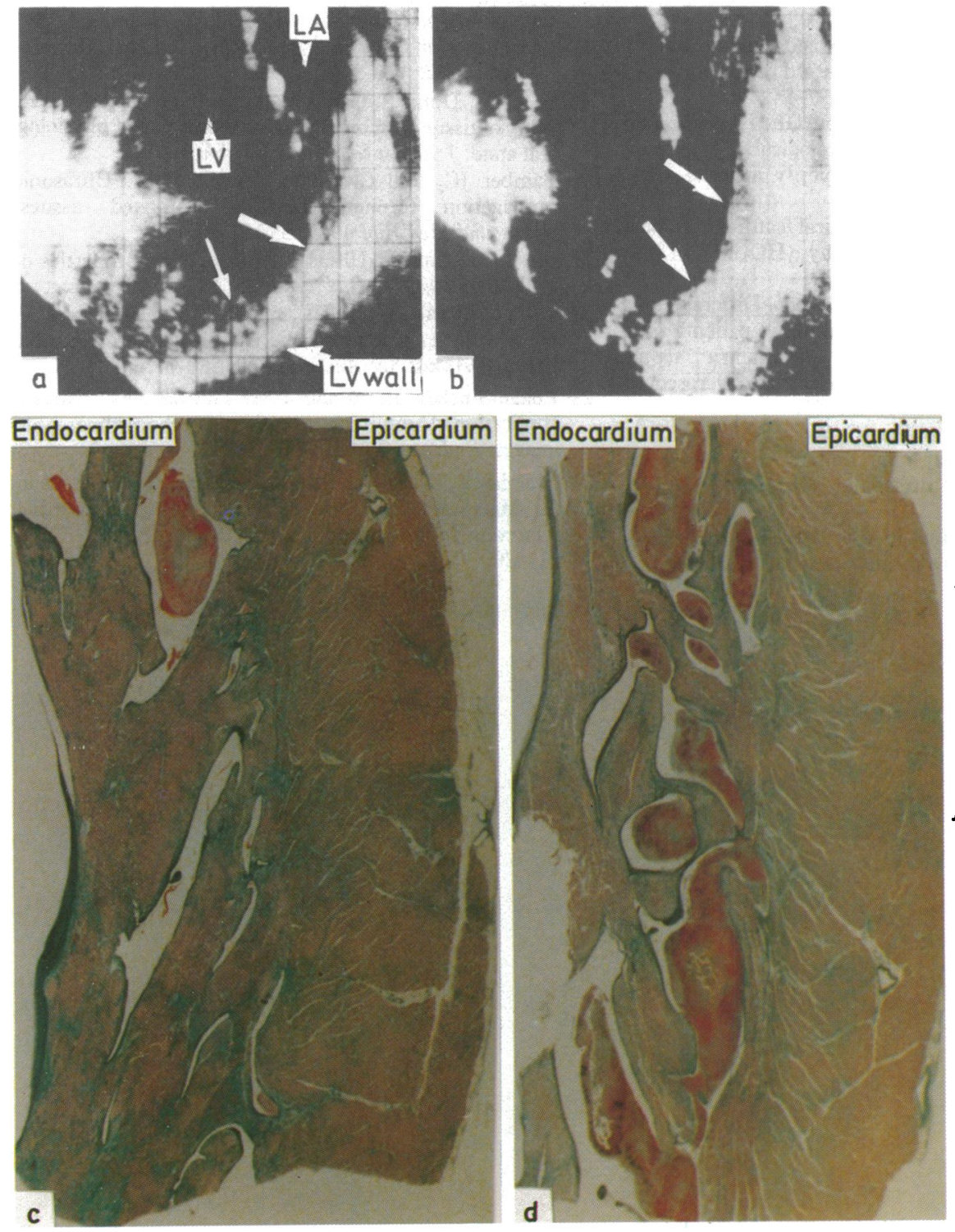

Fig. 12 Cross sectional echocardiograms in a patient with dilated cardiomyopathy during $(a)$ systole and $(b)$ diastole and $((c)$ and $(d)) a$ section of the left ventricular free wall (case 8); (c) shows a section at the basal portion of the left ventricular wall, which corresponds to the site shown by the thick white arrow on $(a)$ and $(d)$ shows the apical portion of the left ventricular wall (thin white arrow on (a)). Scattered fibrous tissues (stained blue) are seen throughout the myocardium with numerous microthrombi. The echo pattern of the left ventricular wall is the same as in the type III echo, but there is a large difference in echo pattern between systole and diastole. ultrasonic diagnosis. Med Ultrasonics 1968; 6: 1-8.

8 Tanaka M. Diagnostic application of the sensitivitygraded-tomogram-pair method for the cardiovascular diseases. Fapanese Foumal of Medical Ultrasonics 1976; 3: 11-8.

9 Okada R. A morphological classification of the idiopathic myocardiopathy and allied cardiac diseases. fpn $_{\text {Circ } \mathcal{F}}$ 1971; 35: 755-63.

10 Tanaka M, Oka S, Ebina T, et al. The diagnostic application of ultrasound to the disease in mediastinal organs: 3 The ultrasono-cardiotomography in living human sub- jects. Sci Rep Res Inst Tohoku Univ [Med] 1967; 14; $1-21$.

11 Olsen EGJ. Postmortem findings and histologic, histochemical, and electron microscopic findings of myocardial biopsies. In: Kaltenbach M, Loogen F, Olsen EGJ, eds. Cardiomyopathy and myocardial biopsy. Berlin: Springer-Verlag, 1978: 52-61.

12 Kunkel B, Lapp H, Kober G, Kaltenbach M. Lightmicroscopic evaluation of myocardial biopsies. In: Kaltenbach M, Loogen. F, Olsen EGLJ, eds. Cardiomyopathy and myocardial biopsy. Berlin: Springer- 
Verlag, 1978: 62-70.

13 Sekiguchi M, Konno S. Diagnosis and classification of primary myocardial disease with the aid of endomyocardial biopsy. Jpn Circ f 1971; 35: 737-54.

14 Van Noorden S, Olsen EGJ, Pearse AGE. Hypertrophic obstructive cardiomyopathy: a histological, histochemical, and ultrastructural study of biopsy material. Cardiovasc Res 1971; 5: 118-31.

15 Pomerance A, Davies MJ. Pathological features of hypertrophic obstructive cardiomyopathy (HOCM) in the elderly. Br Heart $\mathcal{f}$ 1975; 37: 305-12.

16 Maron BJ, Ferrans VJ, Henry WL, et al. Differences in distribution of myocardial abnormalities in patients with obstructive and non-obstructive asymmetric septal hypertrophy (ASH): light and electron microscopic findings. Circulation 1974; 50: 436-46.

17 Mimbs JW, Yuhas DE, Miller JG, Weiss AN, Sobel BE. Detection of myocardial infarction in vitro based on altered attenuation of ultrasound. Circ Res 1977; 41: 192-8.

18 Gibson DG, Logan Sinclair RB. Measurement of regional echo intensity as a means of cardiac tissue charac- terization. In: Hanrath P, Bleifeld W, Seuquet J, eds. Cardiovascular diagnosis by ultrasound. Hague: Martinus Nijhoff, 1982: 141-51.

19 Fields S, Dunn F. Correlation of echographic visualizability of tissue with biological composition and physiological state. F Acoust Soc Am 1973; 54: 809-12.

20 Bamber JC, Hill CR, King JA, Dunn F. Ultrasonic propagation through fixed and unfixed tissues. Ultrasound Med Biol 1979; 5: 159-65.

21 Goss SA, Dunn F. Ultrasonic propagation properties of collagen. Phys Med Biol 1980; 25: 827-37.

22 O'Donnell M, Mimbs JW, Miller JG. Relationship between collagen and ultrasonic backscatter in myocardial tissue. J Acoust Soc Am 1981; 69: 580-8.

23 Logan-Sinclair R, Wong CM, Gibson DG: Clinical application of amplitude processing of echocardiographic images. Br Heart $\mathcal{Y}$ 1981; 45: 621-7.

24 Gramiak R, Waag RC, Schenk EA, Lee PPK, Thomson K, Macintosh P. Ultrasonic detection of myocardial infarction by amplitude analysis. Radiology 1979; 130: 713-20. 